\title{
A Crewed Mission to Apophis Using a Hybrid Bimodal Nuclear Thermal Electric Propulsion (BNTEP) System
}

\author{
David R. McCurdy ${ }^{1}$, Stanley K. Borowski ${ }^{2}$, Laura M. Burke ${ }^{3}$, Thomas W. Packard ${ }^{4}$ NASA Glenn Research \\ Center, Cleveland, $\mathrm{OH} 44135$
}

\begin{abstract}
A BNTEP system is a dual propellant, hybrid propulsion concept that utilizes Bimodal Nuclear Thermal Rocket (BNTR) propulsion during high thrust operations, providing 10's of kilo-Newtons of thrust per engine at a high specific impulse $\left(I_{\mathrm{sp}}\right)$ of $900 \mathrm{~s}$, and an Electric Propulsion (EP) system during low thrust operations at even higher $I_{\mathrm{sp}}$ of around $3000 \mathrm{~s}$. Electrical power for the EP system is provided by the BNTR engines in combination with a Brayton Power Conversion (BPC) closed loop system, which can provide electrical power on the order of 100's of $\mathrm{kW}_{\mathrm{e}}$. High thrust BNTR operation uses liquid hydrogen $\left(\mathrm{LH}_{2}\right)$ as reactor coolant propellant expelled out a nozzle, while low thrust EP uses high pressure xenon expelled by an electric grid. By utilizing an optimized combination of low and high thrust propulsion, significant mass savings over a conventional NTR vehicle can be realized. Low thrust mission events, such as midcourse corrections (MCC), tank settling burns, some reaction control system (RCS) burns, and even a small portion at the end of the departure burn can be performed with EP. Crewed and robotic deep space missions to a near Earth asteroid (NEA) are best suited for this hybrid propulsion approach. For these mission scenarios, the Earth return $\Delta \mathrm{V}$ is typically small enough that $\mathrm{EP}$ alone is sufficient. A crewed mission to the NEA Apophis in the year 2028 with an expendable BNTEP transfer vehicle is presented. Assembly operations, launch element masses, and other key characteristics of the vehicle are described. A comparison with a conventional NTR vehicle performing the same mission is also provided. Finally, reusability of the BNTEP transfer vehicle is explored.
\end{abstract}

\section{Nomenclature}

$\begin{array}{ll}\mathrm{D} \times \mathrm{L} & =\text { diameter by length } \\ \Delta \mathrm{V} & =\text { delta-velocity or change in velocity } \\ \mathrm{He}-\mathrm{Xe} & =\text { Helium-Xenon } \\ \mathrm{klb}_{\mathrm{f}} & =\text { thrust }(1000 \text { pounds force }) \\ \mathrm{km} / \mathrm{m} / \mathrm{kg} & =\text { kilometers } / \text { meters/kilogram } \\ \mathrm{kW} / \mathrm{kJ} & =\text { kilowatts electrical/kilojoules } \\ \mathrm{NASA} & =\text { National Aeronautics and Space Administration } \\ \mathrm{psi} & =\text { pounds per square inch } \\ \mathrm{S} & =\text { seconds } \\ \mathrm{t} & =\text { metric ton }(1 \mathrm{t}=1000 \mathrm{~kg}) \\ \mathrm{UO}_{2}-\mathrm{W} & =\text { Uranium dioxide-Tungsten } \\ \mathrm{UC}_{\mathrm{Z}} \mathrm{ZrC} & =\text { Uranium carbide-Zirconium carbide composite }\end{array}$

\section{Introduction}

A SIDE from the numerous technical issues, one of the main drivers in assessing the feasibility of a deep space mission is total launched mass to low Earth orbit (LEO). A large percentage of the launched mass is the

${ }^{1}$ Mechanical Engineer, Vantage Partners, LLC at Glenn Research Center, 3000 Aerospace Parkway, Brook Park, $\mathrm{OH}$ 44142, Propulsion and Controls Systems Analysis

${ }^{2}$ LTR Branch and Technical Lead, NTP Systems, 21000 Brookpark Road, MS 86-4, AIAA Associate Fellow

${ }^{3}$ Aerospace Engineer, NASA/GRC Trajectory and Mission Analysis

${ }^{4}$ Aerospace Engineer, Vantage Partners, LLC, Trajectory and Mission Analysis

1

American Institute of Aeronautics and Astronautics 
propellant required for the mission. Propellant consumption is related to engine's $\mathrm{I}_{\mathrm{sp}}$, which can be thought of as gas mileage, where the higher the $\mathrm{I}_{\mathrm{sp}}$ the less propellant is consumed. Therefore, by using propulsion systems with higher $I_{\mathrm{sp}}$, overall launched mass can be reduced. The BNTR is such a system with high thrust capability and high $I_{\mathrm{sp}}$, twice that of today's best chemical rocket engines ${ }^{1}$. By combining the BNTR and EP into a hybrid propulsion system, it is possible to achieve even higher weight savings ${ }^{2}$. While EP has a very high $\mathrm{I}_{\mathrm{sp}}$, its thrust is extremely low and is only useful during long duration, in space maneuvers. When coupled with a closed loop BPC, the BNTR can provide the power for the EP, combining both propulsion systems into an innovated design which can ultimately reduce initial mass to orbit.

The core propulsion and power stage in Figure 1 contains all the primary propulsion equipment and is the heart of the hybrid vehicle. The core propulsion systems include three BNTR engines with associated radiation shielding, an EP system with two deployable thrust booms, and a RCS system that has four thruster pods, one at each quadrant. The length of the EP booms is set such that the EP thrusters remain inside the radiation shielded cone, 21.75 degree half angle starting from the BNTR and extending forward. Because the EP thrusters cannot be positioned outside this cone, they are canted 15 degrees from the axis to prevent ion impingement on the core stage surfaces. The corrosive ion stream has a 22.5 degree half angle emanating from the thrusters and extending aft. Canting the thrusters introduces a slight cosine loss to the EP system, which means a little more xenon is needed. The remaining core stage items are the conical truss thrust structure used to attach the BNTR engines and hold a section of the Brayton radiators to the aft end of the core tank. By placing the radiator near the core tank, 30 additional layers of multi-layer insulation (MLI) were used around the actively cooled $\mathrm{LH}_{2}$ tank. Radiators are also included as part of the cryocooling system. Also shown are four smaller xenon tanks, including lines, valves and connections. At the forward end is an intertank adapter structure used for transferring launch and space transit loads and for holding the EP and boom assembly. Attached to the forward end of the tank adapter is a docking mechanism used to complete the interface to the drop element. This interface includes all electrical and fluid quick disconnects necessary to perform an autonomous mating of the two elements in orbit.

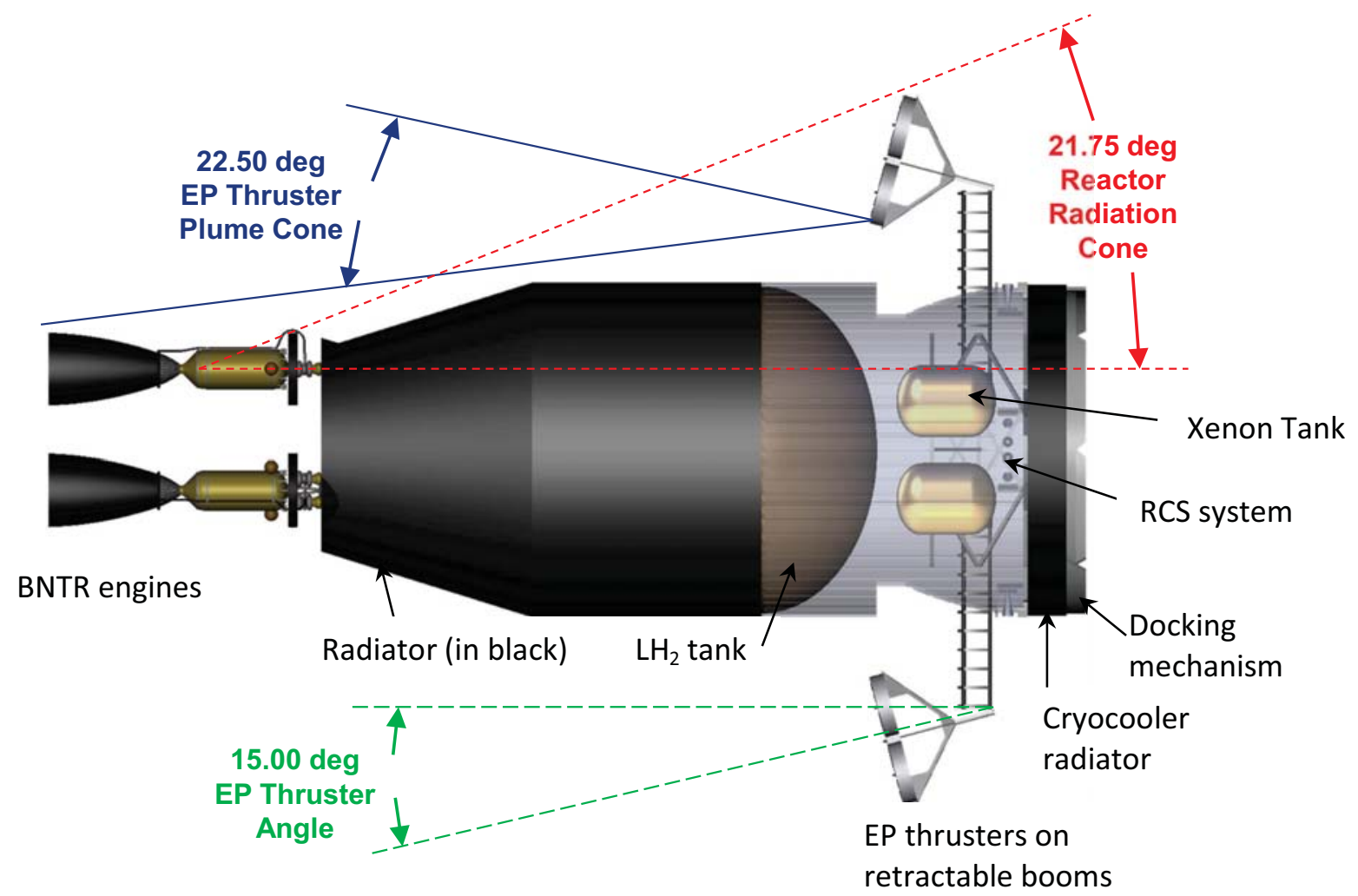

Figure 1. Hybrid core stage element shown deployed.

Aside from the propulsion system, the main difference between the two vehicles is the conventional NTR vehicle's use of photovoltaic arrays (PVAs) for auxiliary spacecraft power, whereas the hybrid vehicle is powered

2

American Institute of Aeronautics and Astronautics 
by the BPC system. This paper quantifies the mass savings that can be achieved by the hybrid system by comparing its performance with a conventional NTR propulsion system for the same mission scenario.

\section{Brayton Power System}

The conventional NTR vehicle's auxiliary power is provided by PVAs located on the core stage and payload elements. The core stage has two $\sim 7 \mathrm{~kW}_{\mathrm{e}}$ Mega-flex arrays, twice the power needed for the cryocoolers, allowing for the possibility of the loss of a single array. Likewise, the payload element and crew life support derive their power from PVAs, designed to provide a nominal output of $\sim 50 \mathrm{~kW}_{\mathrm{e}}$ at the destination site.

Power for the hybrid spacecraft, which also includes cryogenic cooling and crew life support, is provided by three Brayton rotating units. The hybrid BNTEP system schematic is given in Figure 2. A closed-Brayton-cycle engine is capable of producing tens of kilowatts and scaling to hundreds of kilowatts of power. The Brayton engine is well-suited to space nuclear power applications such as BNTR. The He-Xe working fluid is compressed by the compressor then heated by passing through the heat-source heat exchanger, i.e. the fuel elements of the BNTR's reactor core. Work is extracted from the hot, high-pressure gas by the turbine, which powers both the alternator and compressor, all located on a single shaft. A $1300 \mathrm{~K}$ turbine inlet temperature was assumed. The working fluid enters the radiator where it is cooled before repeating the cycle. A second fluid loop pumps coolant through the radiator, where waste heat is radiated to space ${ }^{3}$. Large power output Brayton units require scaling the radiator surface area to meet the greater cooling demands.

In order to provide the $800 \mathrm{~kW}_{\mathrm{e}}$ power needed by the $\mathrm{EP}$ system and $50 \mathrm{~kW}_{\mathrm{e}}$ for life support and cryocooling, each $425 \mathrm{~kW}_{\mathrm{e}}$ Brayton unit is operated at $2 / 3$ of its maximum rated power $\sim 283 \mathrm{~kW}_{\mathrm{e}}$. Operating the units this way allows for the loss of a single unit during the mission, where the remaining units can then be operated at their full $425 \mathrm{~kW}_{\mathrm{e}}$ power level. The required $780 \mathrm{~m}^{2}$ single sided radiator area is located on the hybrid vehicle in two sections, one is supported by the BNTR engine thrust structure and the aft portion of the core tank and the remaining radiator surface is supported by the long saddle truss.

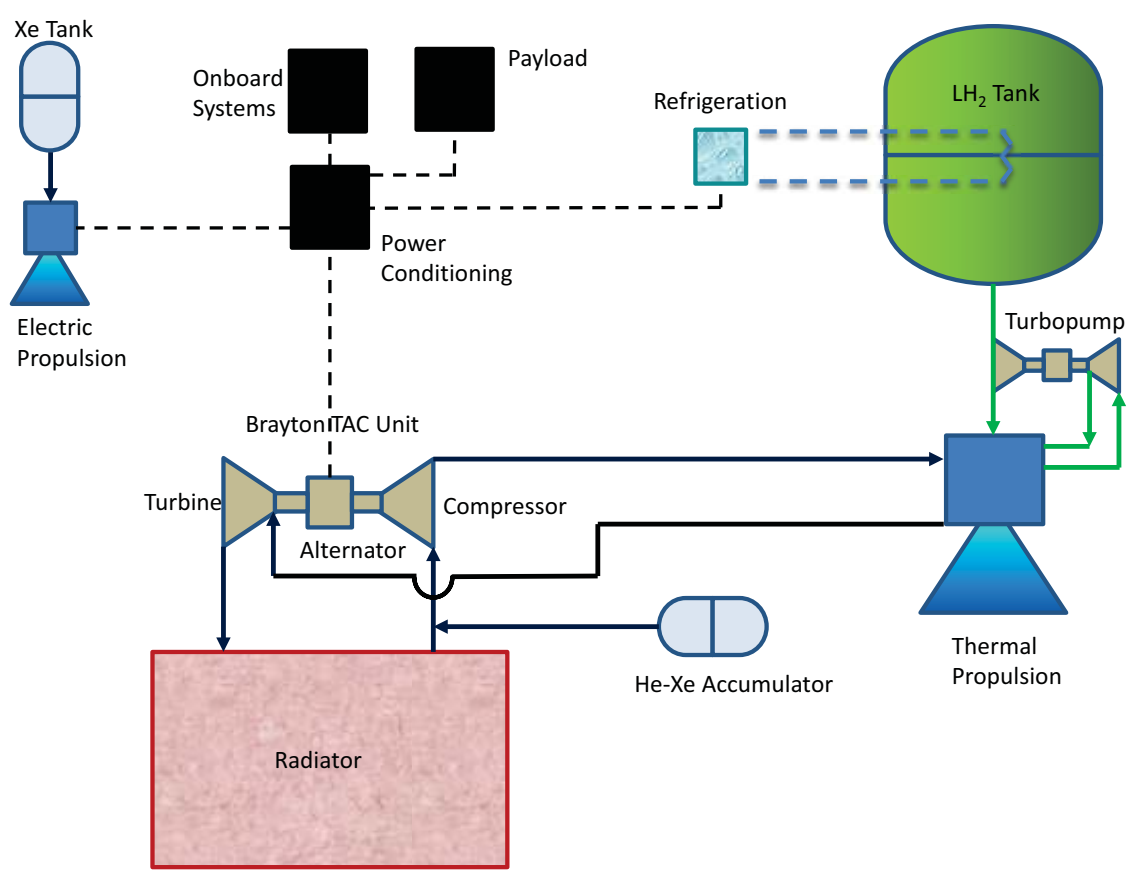

Figure 2. Schematic of the BNTEP system.

\section{Electric Propulsion System}

The EP system uses ion propulsion ${ }^{4,5}$ where electrical potential accelerates a propellant, such as xenon, to high exhaust velocities. Because electrical power is limited, ion engines operate at higher $\mathrm{I}_{\mathrm{sp}}$ than chemical engines but at much lower thrust levels. The advantage of EP is that it can achieve high speeds by operating for long periods of time, on the order of days, weeks, or even months, using much less propellant than other state of the art propulsion 
systems. Since they use less propellant over longer time periods than high thrust BNTR propulsion, they are ideal for low thrust and low $\Delta \mathrm{V}$ mission applications ${ }^{6}$. This makes EP an attractive candidate in tandem with BNTR propulsion for missions to near Earth asteroids.

In an ion thruster, ions are accelerated by electrostatic forces. The electric fields used for acceleration are generated by electrodes positioned at the downstream end of the thruster. Each set of electrodes, called ion optics or grids, contains thousands of coaxial apertures. Each set of apertures acts as a lens that electrically focuses ions through the optics. NASA's ion thrusters use a two-electrode system, where the upstream electrode (called the screen grid) is charged highly positive, and the downstream electrode (called the accelerator grid) is charged highly negative. Since the ions are generated in a region of high positive and the accelerator grid's potential is negative, the ions are attracted toward the accelerator grid and are focused out of the discharge chamber through the apertures, creating thousands of ion jets. The stream of all the ion jets together is called the ion beam. The thrust force is the force that exists between the upstream ions and the accelerator grid. The exhaust velocity of the ions in the beam is based on the voltage applied to the optics. While a chemical rocket's top speed is limited by the thermal capability of the rocket nozzle, the ion thruster's top speed is limited by the voltage can be applied to the ion optics ${ }^{7}$.

The basic components of an EP system are the thrusters and gimbals, xenon feed and propellant storage, electrical distribution and control, and the structure needed to hold these components during flight. Propellant is fed to the thrusters via the feed system. Xenon is the propellant of choice because it has a relatively low first ionization potential $(12.1 \mathrm{~kJ} / \mathrm{mol})$ and has a high charge-to-mass ratio $\left(7.14 \times 10^{5}\right.$ coulomb/ $\left.\mathrm{kg}\right)$, giving it a high exhaust velocity. Since Xe is chemically inert, it is more easily used without corrosion to the engine components. It can be stored as a liquid cryogen under high pressure yet be easily converted back to a gas to feed the engine. Thrust direction is controlled by gimballing the thrusters. The EP thrusters and gimbal system must be stowed during launch on a telescoping boom, which is positioned forward of the $\mathrm{LH}_{2}$ core tank. The telescoping boom is based on current state-of-the-art design where the boom can be stowed within $2 \%$ of its fully extended length. The thruster gimbal is necessary to cant the engines to prevent the ion plume from damaging downstream components. Hall type thrusters were not used in the BNTEP vehicle design because their plume half angle of 45 degrees was too large.

\section{Asteroid Survey Vehicle (ASV)}

The conventional NTR ASV has been described in detail in other technical articles ${ }^{8}$ and is not detailed in this paper. The hybrid BNTEP concept has also been evaluated previously for a Mars mission ${ }^{9}$. The BNTEP and conventional ASV are shown to scale in Figure 3. Because the assembled ASV is too large and heavy for a single Space Launch System (SLS) vehicle to lift, it must be separated into three elements: (1) the core propulsion stage which contains propulsion and power systems, (2) the saddle truss and drop tank assembly, and (3) the crewed payload and life support element. These three spacecraft elements are roughly of similar size and/or weight and each are launched from Earth to LEO using the SLS Block IA with $110 \mathrm{t}$ lift capability. The first element to be launched is the core stage. Power for the core stage is provided by the BPC system for the BNTEP vehicle and by PVAs for the conventional vehicle. Once placed in orbit, station keeping and rendezvous and docking (R\&D) is provided by the onboard RCS using hypergolic propellant. To prevent significant loss of cryogenic $\mathrm{LH}_{2}, \mathrm{the} \sim 5 \mathrm{~kW}$ core stage cryocooler is active continuously. The aft conical portion of the BPC radiator has sufficient area to provide cooling the power system prior to mating with the drop tank and truss assembly, and its distance from the core tank limits the amount of the waste heat input to the tank.

Thirty days after the core stage is launched, the saddle truss and drop tank assembly is launched. This stage has onboard batteries for keep-alive power until it is docked with the core stage, scheduled to be within 12 hours after reaching orbit. There is no cryocooler or RCS for this element, and its boil off period from launch till vehicle departure is 67 days. Orbital station maintenance and attitude control is provided by on board control moment gyros $(\mathrm{CMG})$ until docked with the core stage. The payload element is launched thirty days after the saddle/drop assembly. For the conventional vehicle, it uses PVAs for power and an onboard RCS for attitude control. For the hybrid vehicle, this element is powered by a battery system until docked with the core and saddle elements when the BPC system provides its power. Once the autonomous orbital assembly is complete, the crew arrives in the Multipurpose Crew Vehicle (MPCV) and docks to the Transit Habitat (TransHab) module. Now that the ASV is in its mission configuration, the crew begins a 7 day checkout involving inflating the TransHab and deploying propulsion and power systems. 

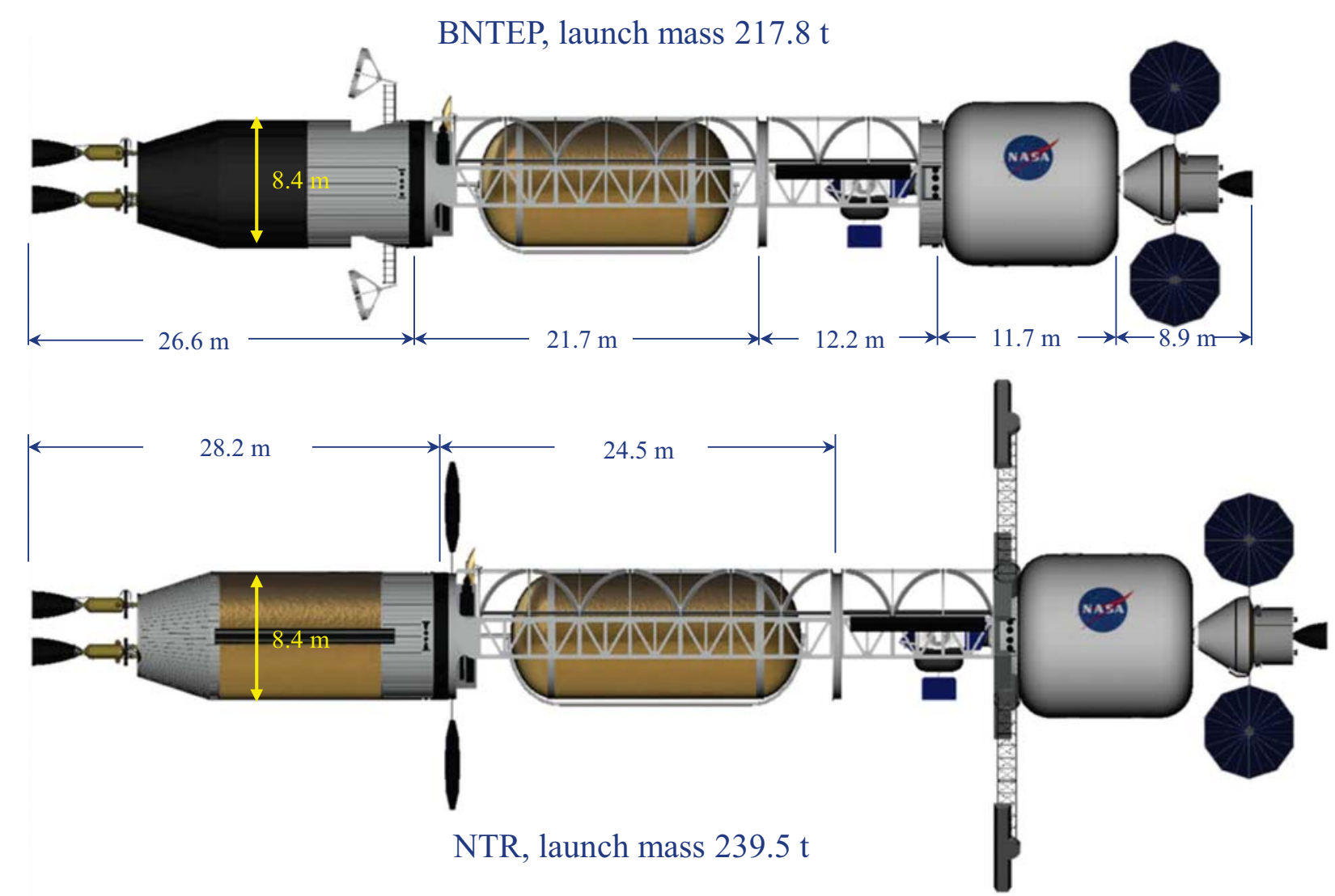

Figure 3. Relative size of the BNTEP and conventional NTR ASV. Power and propulsion systems deployed.

The launch configurations of the three elements within the SLS fairing are shown in Figure 4. Although the core stage is shown inverted, it can be launched engines aft using a longer payload adapter. The second element is designed so that the saddle truss hangs from the tank and the main load path is through the drop tank and not the truss. The third launch element is the crew payload element which includes a deflated TransHab module and food stores. It also has a short $12 \mathrm{~m}$ long saddle truss that is used to support a 2 person asteroid excursion vehicle known as the multi-mission space excursion vehicle (MMSEV). 

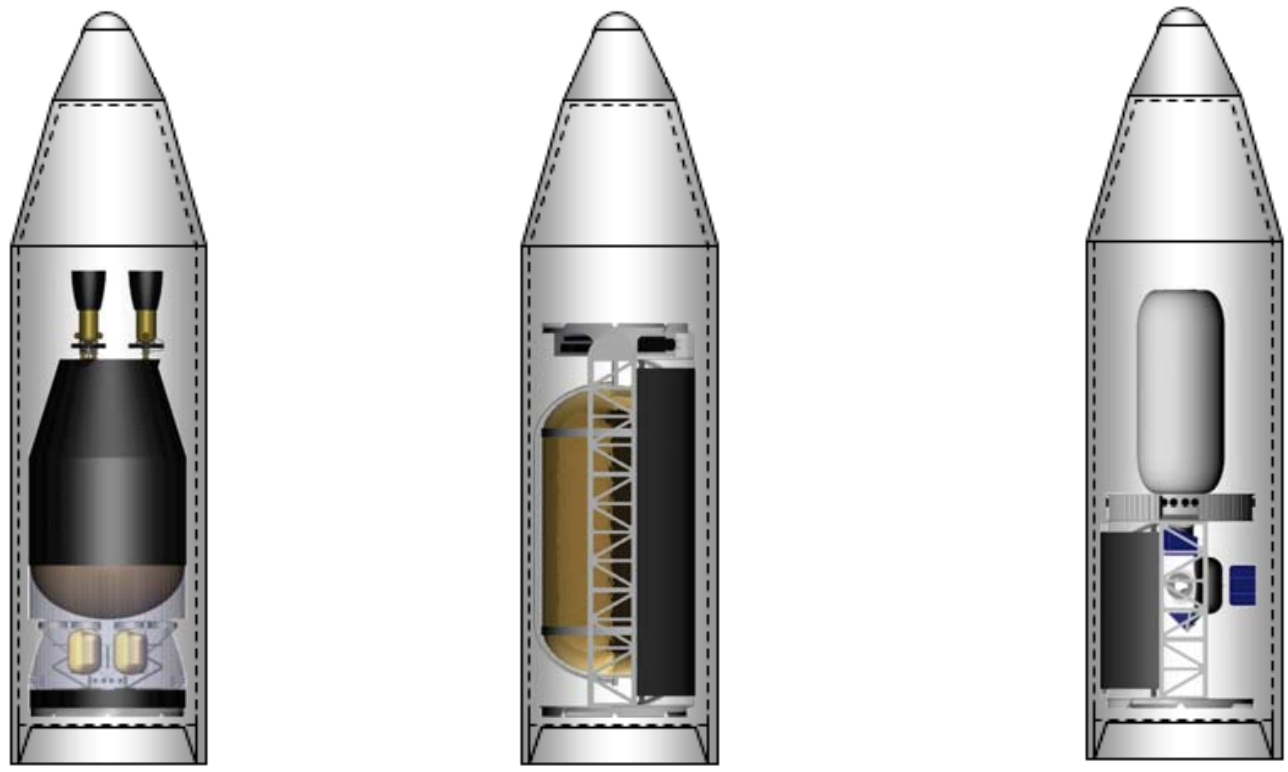

Figure 4. Launch Configurations of core stage, drop tank, and payload element

The BNTEP ASV and is major components are illustrated in Figure 5.

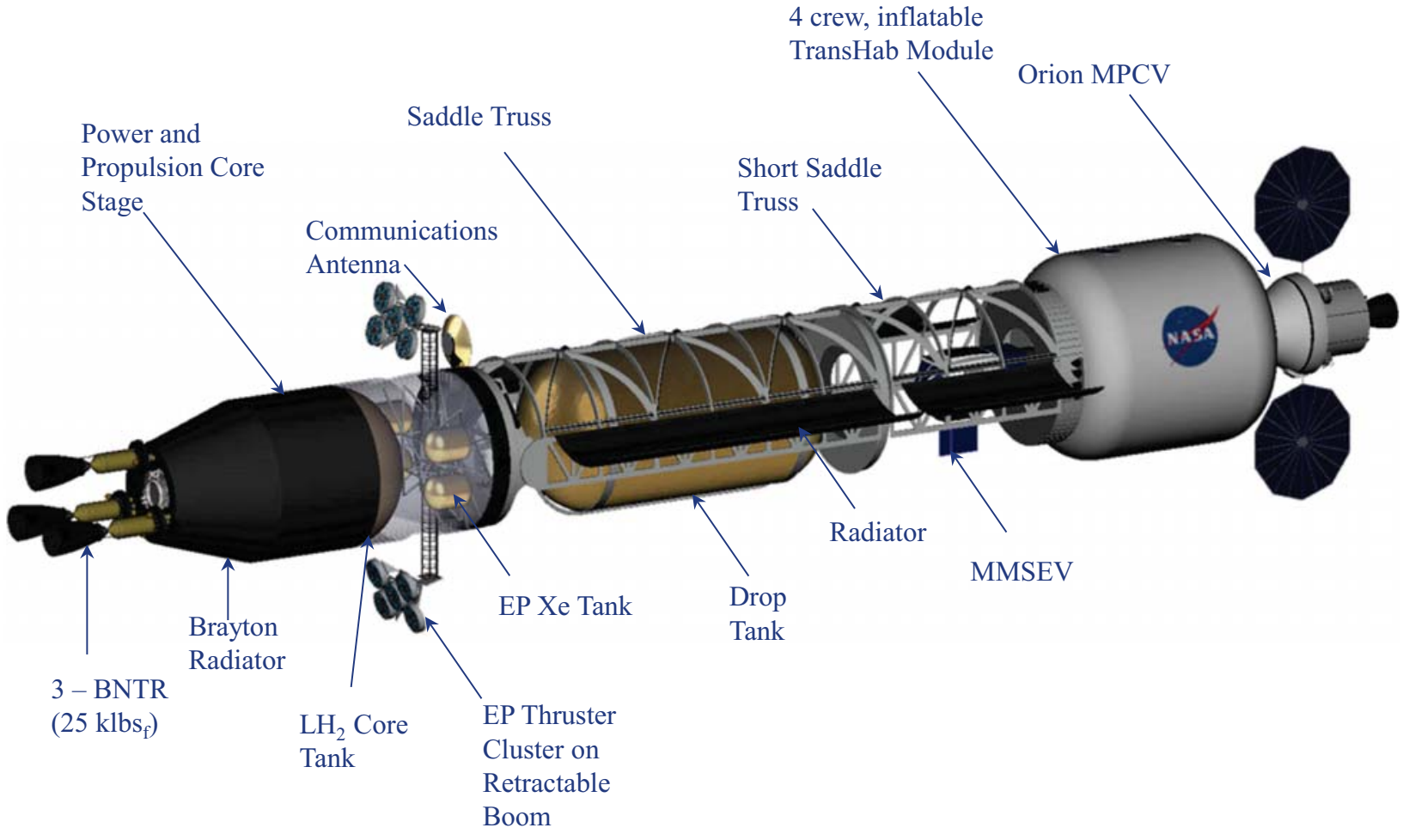

Figure 5. Isometric view of BNTEP ASV and its major components. 


\section{Crewed Apophis Mission Scenario}

With an average diameter of roughly $325 \mathrm{~m}$, Apophis is a relatively large, possibly irregularly shaped NEA discovered in 2004 that initially caused concern because of a remote probability of striking the Earth in 2029. It is estimated that the 2029 encounter will be sufficiently close to Earth that ocean tides could alter its spin rate ${ }^{10}$, currently observed at 30.4 hours per revolution. Improved observations determined the possibility of an Earth or Moon collision in 2029 would not occur. However, a small possibility remained that if in 2029 Apophis passes Earth at a distance of $30405 \mathrm{~km}$, it would pass through a gravitational keyhole that could set up a future impact on April 13,2036 ${ }^{11}$. Further radar observations have since ruled out an Earth impact in 2036. However, a small impact possibility still remains for the 2068 encounter. Adding to the uncertainty of a future collision is the continuous, non-gravitational force called the Yarkovsky effect ${ }^{12}$. This effect is the net force between diurnal solar radiation absorbed by the asteroid and its re-emission back into space. The Yarkovsky effect is difficult to quantify because of the numerous variables such as rotation period, pole orientation, thermal properties, mass, shape, and size of the body. In order to quantify this effect and study the structure and composition of Apophis, close-up observation with tracking equipment and a sample return mission is needed.

A one year roundtrip crewed mission to study Apophis could occur in 2028 just prior to its closest approach to Earth $^{13}$. The crewed BNTEP mission would look like the illustration ${ }^{14}$ of Figure 6. Essentially, three SLS Block IA launches would be required to place the spacecraft into orbit in 3 separate elements. Once the three elements have docked to one another, a fourth launch delivers the Orion MPCV and crew. After the assembled ASV is fully deployed and checked out, the crew is ready to depart on their mission. The trans-NEA injection (TNI) thrust will be provided solely by the three BNTR engines in a dual perigee burn sequence that minimizes gravitational loss. Following the first perigee burn, all of the propellant in the drop tank is consumed and the tank and CMG's are jettisoned during a once around the Earth elliptical orbit. At the proper orbital position, the second burn occurs, using a partial amount of propellant in the core tank. The spacecraft is now on a trajectory to the Apophis.

Sometime prior to the arrival, a $65 \mathrm{~m} / \mathrm{s} \Delta \mathrm{V}$ MCC burn is executed for the conventional vehicle. This burn is to be provided by the RCS. A MCC is not needed for the BNTEP vehicle since the EP system is operating over a longer period of time with smaller thrust that allows for more orbital precision. Following the MCC the NTR vehicle has now been precisely aimed for arrival to Apophis. Once the spacecraft has been placed in a parking orbit around the asteroid, visual inspections, field measurements, and sample extractions can be performed during the 30 day stay time. Two astronauts perform several sorties using the MMSEV, gathering samples and placing scientific devices on the asteroid surface. These devices will enable ground support to characterize the mechanical and thermal properties of the asteroid and provide accurate measure of its orbit and spin rate as well as radiation signatures. With final samples from multiple sites in hand, the astronauts transfer back to the TransHab to prepare for the return trip. There are no planned jettison events at this time. However, in an emergency condition, the MMSEV and perhaps any consumable waste can be left orbiting Apophis in order to reduce the required return propellant mass.

A week prior to completing the 30 day stay, the crew prepares for the return voyage, including science equipment and sample stowage, vehicle checkout and systems verification. Once the ASV checklist is complete, the hybrid vehicle will use the EP for the trans-Earth injection (TEI) burn to spiral from the NEA and return to Earth. This burn occurs with the low thrust system over a period of about 1 month. About halfway back to Earth another low thrust MCC burn is performed for the conventional NTR vehicle in order to precisely aim the spacecraft for Earth rendezvous. A few days prior to arrival, the crew makes their way into the MPCV and begin preparations for capsule splash down. The MPCV is separated from the ASV and returns to Earth for landing in the ocean while the ASV is safely disposed in deep space for the expendable case or captured in Earth orbit for the reusable case. The service module (SM) of the MPCV must perform a slowdown burn to ensure an entry velocity of no greater than $12.5 \mathrm{~km} / \mathrm{s}$ to be within heat shield limitations. 


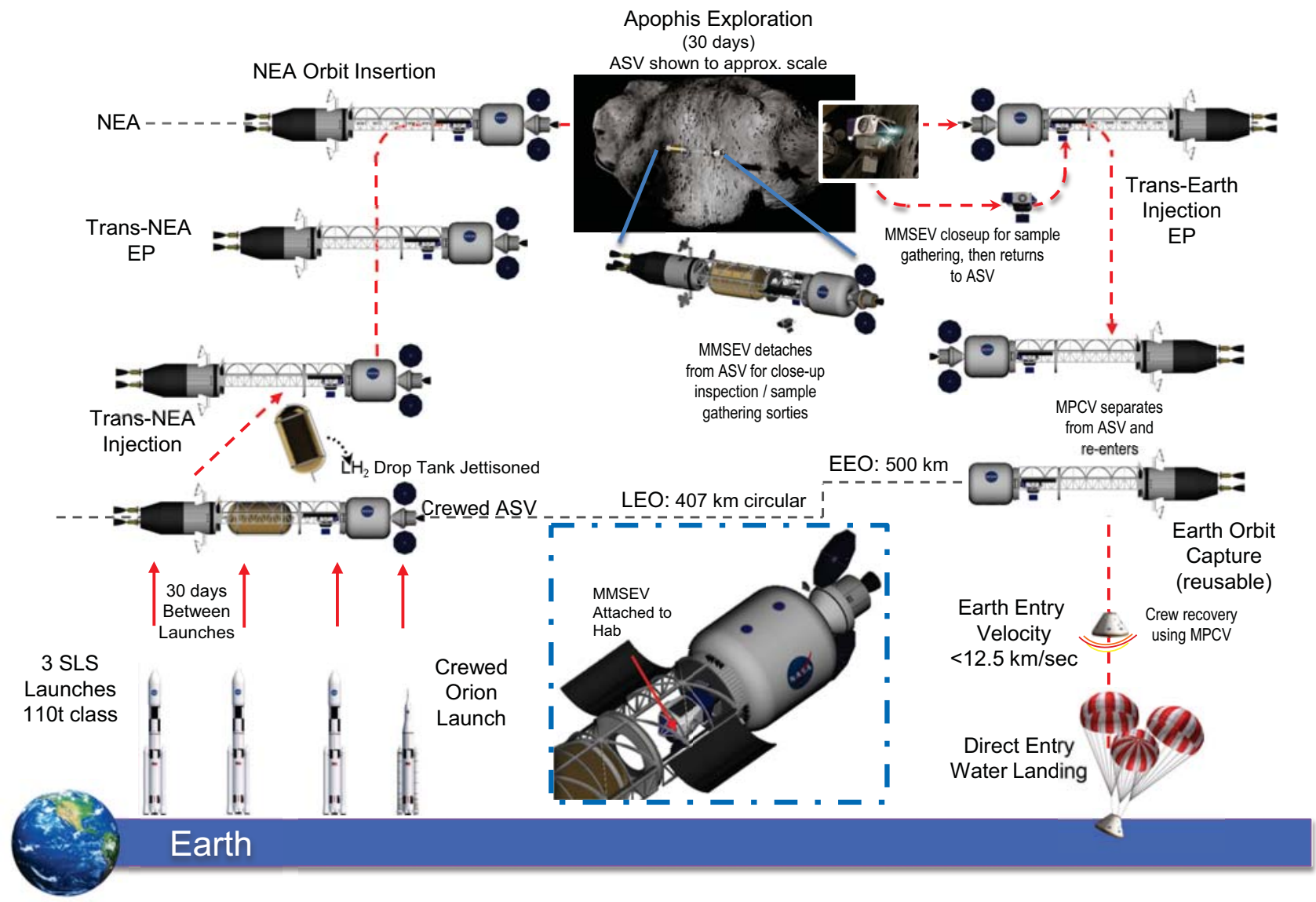

Figure 6. Overview of the BNTEP Apophis mission profile.

\section{Ground Rules and Assumptions}

The Apophis mission and NTR transportation system ground rules and assumptions used in this study are summarized in Tables 1 and 2. Table 1 gives information concerning operational and mission destination characteristics, including parking orbits at Earth. Besides the large bulk $\Delta \mathrm{V}$ maneuvers required for Earth departure, destination arrival and return, additional smaller RCS $\Delta \mathrm{V}$ maneuvers are required for rendezvous and docking of the vehicle elements during the LEO assembly phase and for orbital maintenance. These are included because they affect the size and dry weight of RCS for the ASV.

The trajectory optimization program COPERNICUS ${ }^{15}$ was used to perform the optimization analysis for the 1 year expendable and reusable BNTEP missions. Impulsive burns were used to model the high thrust NTR and BNTR operations and finite burns were used to model the low thrust EP operations. The dual perigee burns for Earth departure were performed exclusively with either NTR or BNTR. The remaining burns, asteroid capture, trans-Earth injection, and Earth capture, were done using EP. The total time of flight was constrained to be 365 days or less and the stay time at Apophis was constrained to be 30 days. 
Table 1. Ground Rules and Assumptions for Sizing the Crewed Mission to Apophis.

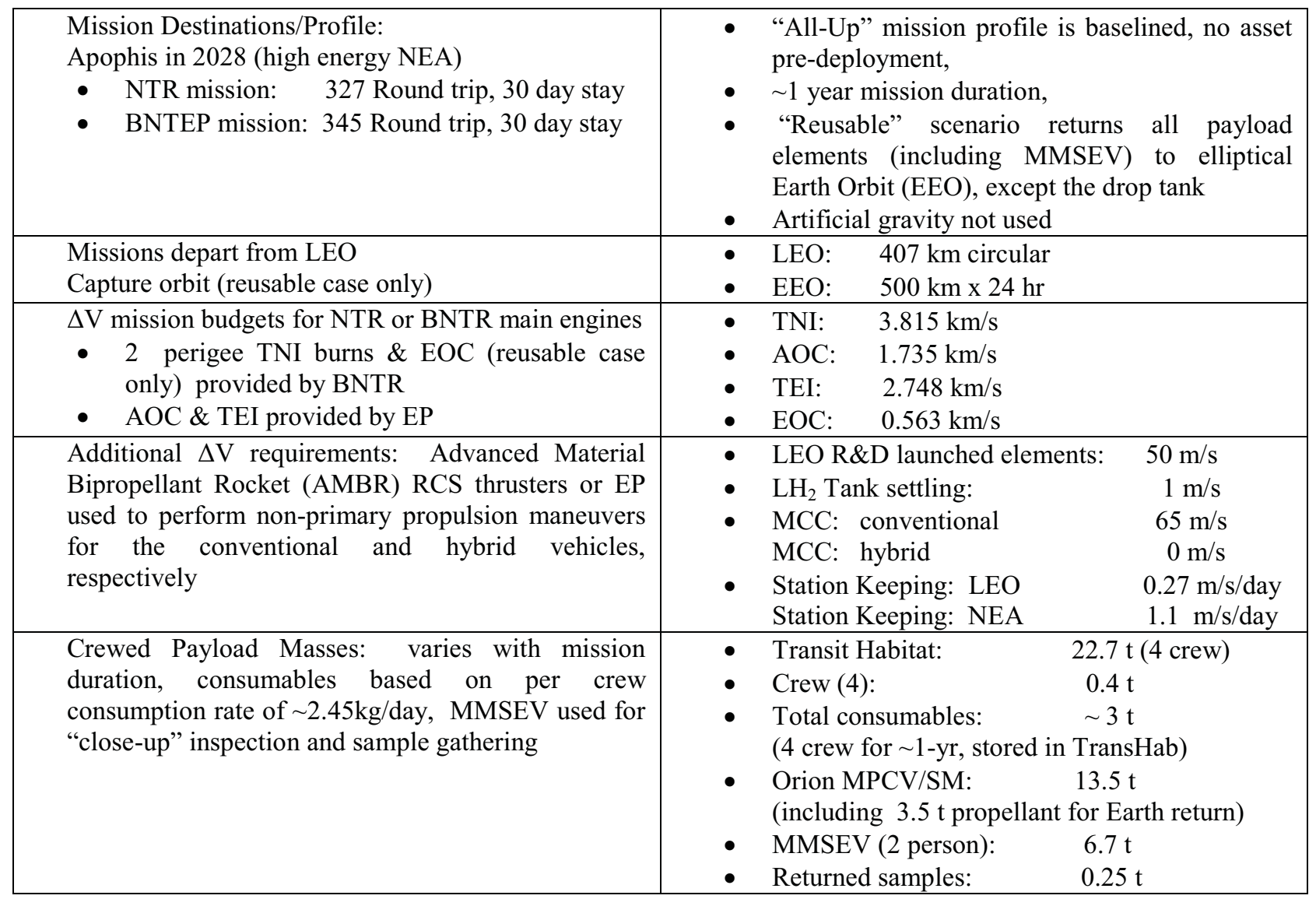

Table 2 lists the key transportation system ground rules and assumptions, pertaining to engine characteristics, propellant margins, the material systems and safety factors used in tanks and trusses. A 3 engine cluster of $25 \mathrm{klb}_{\mathrm{f}}$ "ESCORT/TRITON-class" BNTR's ${ }^{16}$ is baselined. The total mission $\mathrm{LH}_{2}$ propellant loading plus performance reserve, cool down, and trapped residuals is stored in 2 tanks known as the core and drop. The drop tank is not cryocooled and boil off is calculated for the 67 day duration that propellant is held in this tank. For smaller auxiliary maneuvers, storable bipropellant RCS is used, using a split configuration between the fore and aft launch elements. Approximately half of the bipropellant load, 16 of the 32 total thrusters, and half the required tanks are placed on the core propulsion stage at the forward ring. The other half is located on the forward ring of the $12 \mathrm{~m}$ truss just behind the TransHab module.

The EP system is also located on the core stage between the $\mathrm{LH}_{2}$ tank and RCS. The fifty $20 \mathrm{~kW}_{\mathrm{e}}$ EP thrusters, twenty-five located at the top and 25 located at the bottom are placed on retractable telescoping booms so that the dynamic envelope of the fairing is not penetrated during launch.

The $\mathrm{LH}_{2}$ propellant is stored in two state of the art aluminum-lithium (Al-Li) tanks. Tank sizing assumes a 30 psi ullage pressure, a launch load of $5 \mathrm{~g}$ axial $/ 2.5 \mathrm{~g}$ lateral with a safety factor of 1.5 . An additional $3 \%$ volume is included as an ullage factor. The cryogenic tanks assume a spray-on foam insulation (SOFI)/MLI thermal protection system (TPS) for both tanks. The core tank has a zero boil-off (ZBO) system for liquid preservation for the long duration flight. The ZBO is powered by the PVAs for the conventional NTR system and BPC units for the hybrid vehicle. Thus, the BNTEP vehicle utilizes several systems or combination of systems that require a slightly greater technological level to develop than the conventional NTR vehicle. 
Table 2. Ground Rules and Assumptions for the Transportation System.

\begin{tabular}{|c|c|}
\hline NTR System characteristics & 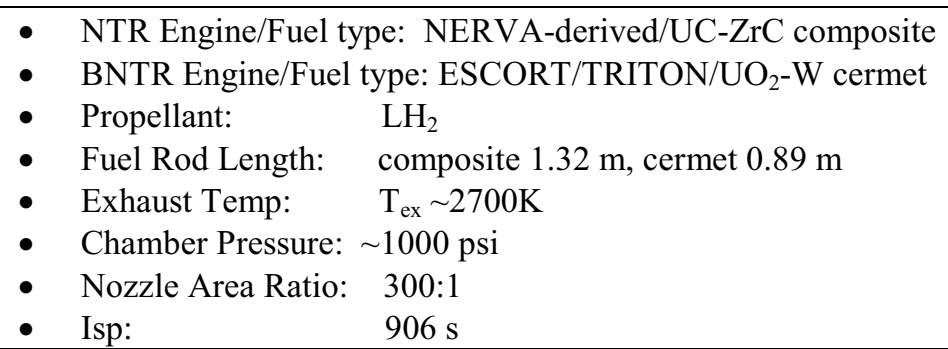 \\
\hline $\mathrm{LH}_{2}$ Propellant Margins & $\begin{array}{lll}\text { - } & \text { Cooldown: } & 3 \% \text { of usable } \mathrm{LH}_{2} \text { propellant } \\
\text { - } & \text { Performance Reserve: } & 1 \% \text { of } \Delta \mathrm{V} \\
\text { - } & \text { Tank trapped residuals: } & 2 \% \text { of total propellant capacity } \\
\end{array}$ \\
\hline EP System characteristics & 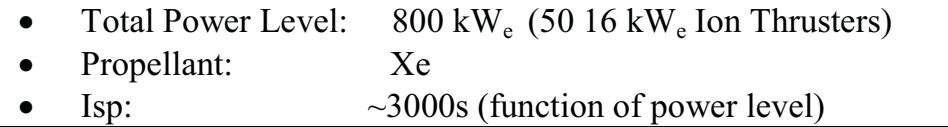 \\
\hline EP Propellant Margins & $\begin{array}{l}\text { - Performance Reserve: } 1 \% \text { of } \Delta \mathrm{V} \\
\text { - Tank trapped residuals: } 2 \% \text { of total propellant capacity }\end{array}$ \\
\hline Cryogenic tanks and Passive TPS & $\begin{array}{lll} & \text { Material: } & \text { Aluminum-Lithium }(\mathrm{Al} / \mathrm{Li}) \\
\text { - } & \text { Tank OD: } & 8.4 \mathrm{~m} \\
\text { - } & \text { Geometry: } & \text { Cylindrical barrel, } \sqrt{ } 2 / 2 \text { ellipsoidal domes } \\
\text { - } & \text { Insulation: } \quad 1 " \text { SOFI }\left(\sim 0.78 \mathrm{~kg} / \mathrm{m}^{2}\right) \\
& 60-90 \text { layers MLI }\left(\sim 0.90-1.2 \mathrm{~kg} / \mathrm{m}^{2}\right) \\
\text { - } & \text { Saddle truss is } 5 \mathrm{~m} \text { longer than the drop tank } \\
\end{array}$ \\
\hline $\begin{array}{l}\text { Active Cryo-Fluid Management/ZBO } \\
\mathrm{LH}_{2} \text { propellant system }\end{array}$ & $\begin{array}{l}\text { - Reverse turbo-Brayton ZBO cryo-cooler on core tank only, } \\
\text { powered by PVAs or BPC } \\
\text { - ZBO system mass and power driven by core tank heat input }\end{array}$ \\
\hline $\begin{array}{l}\text { Mass Growth Allowance (MGA) on } \\
\text { dry weight items }\end{array}$ & $\begin{array}{l}\text { - } 30 \% \text { on NTR systems and all composite structures (e.g. } \\
\text { saddle truss) } \\
\text { - } 15 \% \text { on established propulsion and spacecraft systems (e.g. } \\
\text { EP, metallic propellant tanks, radiation shields) }\end{array}$ \\
\hline Power Systems & $\begin{array}{l}\text { - BPC for BNTEP vehicle sized for } 850 \mathrm{~kW}_{\mathrm{e}} \text {. PVAs for } \\
\text { conventional NTR vehicle sized for } 50 \mathrm{~kW}_{\mathrm{e}} \text { at NEA with } 2 \\
\text { PVAs to provide } \sim 6 \mathrm{~kW}_{\mathrm{e}} \text { power for } \mathrm{ZBO} \text { coolers on core } \\
\text { stage } \\
\text { - Preassembly keep alive power supplied by lithium ion } \\
\text { battery system }\end{array}$ \\
\hline $\begin{array}{l}\text { SLS Launch Requirements } \\
\text { - } \quad \text { Lift Capacity to LEO } \\
\text { - } \quad \text { Stage size (D x L) }\end{array}$ & $\begin{array}{l}\text { - } \quad 110 \mathrm{t} \\
\quad 8.4 \mathrm{~m} \mathrm{D} \times 30 \mathrm{~m} \mathrm{~L} \text { (into the nosecone envelope, } 26 \mathrm{~m} \text { for the } \\
\text { full cylinder) }\end{array}$ \\
\hline
\end{tabular}

\section{Results}

The detailed masses of each of the launch elements are given in Table 3 for both the hybrid BNTEP mission vehicle and for the conventional NTR vehicle. Individual launch element masses were kept below $110 \mathrm{t}$ which was the assumed launch vehicle limit. This was accomplished by locating propellant between the drop and core tank and altering the split on the dual perigee burn to ensure the drop tank can be jettisoned after the first burn. 
Table 3. Weight of BNTEP and NTR ASV (t).

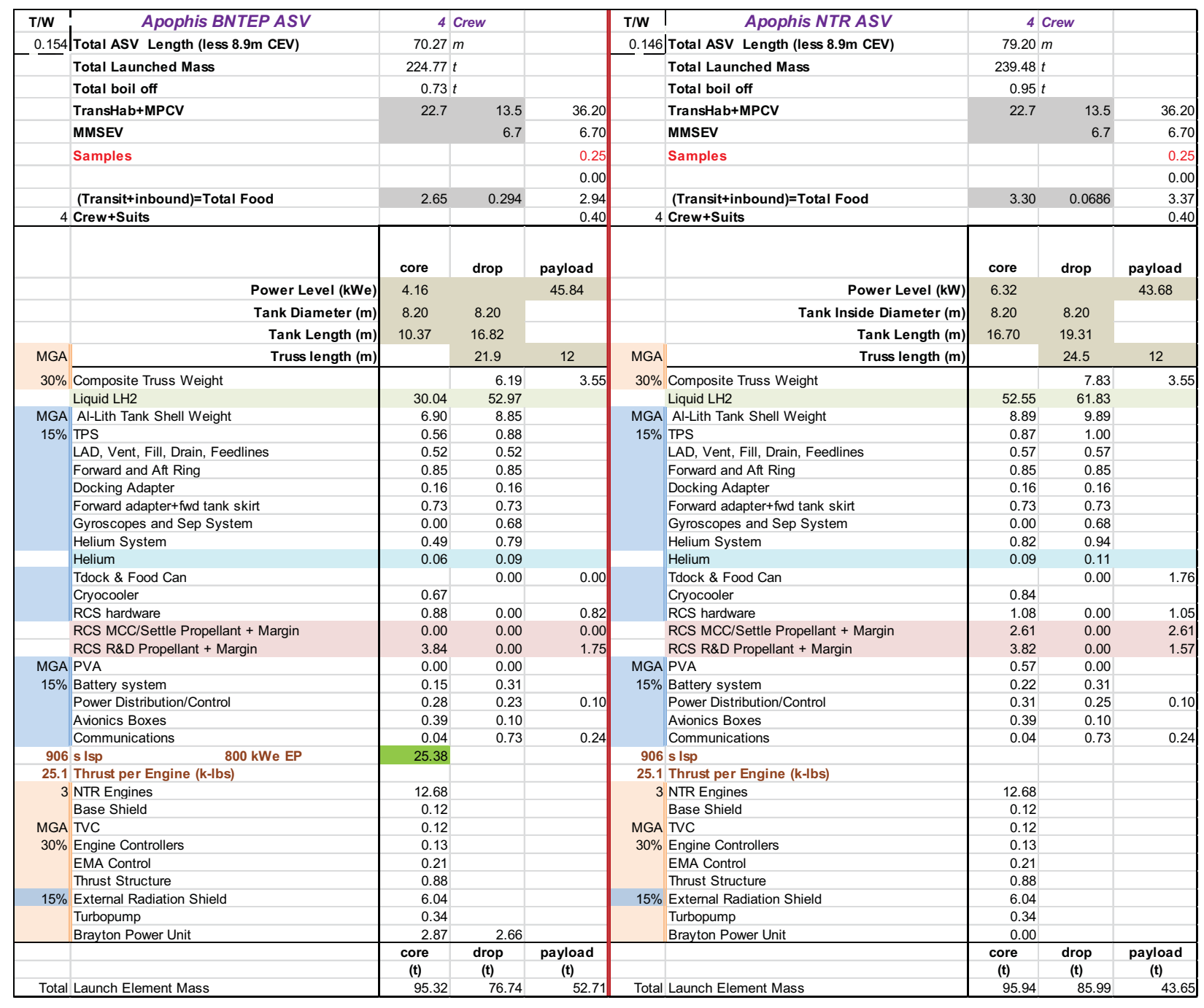

The heaviest launch element as expected is the core stage, since this stage carries all the main propulsion systems. The EP system weighs $\sim 25.4 \mathrm{t}$ of which $\sim 19 \mathrm{t}$ is xenon propellant. The dry mass of the entire conventional NTR vehicle is $\sim 114 \mathrm{t}$, which is actually less than the hybrid vehicle dry mass of $\sim 117 \mathrm{t}$. The saddle truss for the hybrid ASV is about $2.6 \mathrm{~m}$ shorter than the conventional vehicle. However, the BNTEP dry mass is still greater due to the added mass of the Brayton units and the EP system used on the hybrid vehicle. In spite of the higher dry mass, the hybrid vehicle is $\sim 14.7 \mathrm{t}$ lighter due to the total mass of the propellant required for each vehicle.

In addition, the BNTEP approach allows for the possibility of introducing a reusable architecture into the vehicle design. By stretching the drop tank and the saddle truss, sufficient propellant is made available to bring the ASV back into a $500 \mathrm{~km} \times 24 \mathrm{hr}$ elliptical Earth orbit. For this design the total launched mass reaches $\sim 261 \mathrm{t}$. Table 4 lists the pertinent masses of the vehicle systems for the BNTEP reusable vehicle. The maximum mass per element remains within the $110 \mathrm{t}$ launch mass ground rule. The reusable option of the NTR ASV was unable to close within the ground rules. 
Table 4. Weight of Reusable 4 crew BNTEP ASV to Apophis (t).

\begin{tabular}{|c|c|c|c|c|}
\hline \multirow{2}{*}{$\begin{array}{c}T / W \\
0.132 \\
\end{array}$} & Reusable Apophis BNTEP ASV, 4 crew & \multicolumn{3}{|c|}{$25 \mathrm{k} N T R$} \\
\hline & Total ASV Length (less 8.9m CEV) & \multicolumn{2}{|c|}{$77.46 \mathrm{~m}$} & \\
\hline & Total Launched Mass & \multicolumn{2}{|l|}{$261.25 t$} & \\
\hline & Total boil off & \multicolumn{2}{|l|}{$0.95 t$} & \\
\hline & TransHab+MPCV & \multirow{2}{*}{\multicolumn{2}{|c|}{$\begin{array}{r}13.5 \\
6.7\end{array}$}} & 36.20 \\
\hline & MMSEV & & & 6.70 \\
\hline & Samples & & & 0.25 \\
\hline & & & & 0.00 \\
\hline & (Transit+inbound $)=$ Total Food & 3.27 & 0.294 & 3.57 \\
\hline & 4 Crew+Suits & & & 0.40 \\
\hline & & core & drop & payload \\
\hline & Power Level (kWe) & 4.70 & \multirow[b]{2}{*}{8.20} & 45.30 \\
\hline & Tank Inside Diameter $(\mathrm{m})$ & 8.20 & & \\
\hline & Tank Length $(m)$ & 11.96 & 22.50 & \\
\hline MGA & Truss length $(m)$ & & 27.5 & 12 \\
\hline \multirow{2}{*}{$30 \%$} & Composite Truss Weight & & 9.28 & 3.55 \\
\hline & Liquid LH2 & 35.67 & 73.18 & \\
\hline MGA & Al-Lith Tank Shell Weight & 7.44 & 11.78 & \\
\hline \multirow[t]{13}{*}{$15 \%$} & TPS & 0.64 & 1.16 & \\
\hline & LAD, Vent, Fill, Drain, Feedlines & 0.63 & 0.63 & \\
\hline & Forward and Aft Ring & 0.85 & 0.85 & \\
\hline & Docking Adapter & 0.16 & 0.16 & \\
\hline & Forward adapter+fwd tank skirt & 0.73 & 0.73 & \\
\hline & Gyroscopes and Sep System & 0.00 & 0.68 & \\
\hline & Helium System & 0.54 & 1.01 & \\
\hline & Helium & 0.06 & 0.12 & \\
\hline & Tdock \& Food Can & & 0.00 & 0.00 \\
\hline & Cryocooler & 0.72 & & \\
\hline & RCS hardware & 0.88 & 0.00 & 0.82 \\
\hline & RCS MCC/Settle Propellant + Margin & 0.00 & 0.00 & 0.00 \\
\hline & RCS R\&D Propellant + Margin & 3.84 & 0.00 & 1.75 \\
\hline MGA & PVA & 0.00 & 0.00 & \\
\hline \multirow[t]{4}{*}{$15 \%$} & Battery system & 0.17 & 0.31 & \\
\hline & Power Distribution/Control & 0.34 & 0.28 & 0.10 \\
\hline & Avionics Boxes & 0.39 & 0.10 & \\
\hline & Communications & 0.04 & 0.73 & 0.24 \\
\hline 906 & $800 \mathrm{kWe}$ EP & 27.77 & & \\
\hline \multicolumn{5}{|c|}{ 25.1 Thrust per Engine (k-lbs) } \\
\hline & 3 NTR Engines & 12.68 & & \\
\hline & Base Shield & 0.12 & & \\
\hline MGA & TVC & 0.12 & & \\
\hline \multirow[t]{3}{*}{$30 \%$} & Engine Controllers & 0.13 & & \\
\hline & EMA Control & 0.21 & & \\
\hline & Thrust Structure & 0.88 & & \\
\hline \multirow[t]{5}{*}{$15 \%$} & External Radiation Shield & 6.04 & & \\
\hline & Turbopump & 0.34 & & \\
\hline & Brayton Power Unit & 2.87 & 2.66 & \\
\hline & & core & drop & payload \\
\hline & Tank Fraction & $(\mathrm{t})$ & $(\mathrm{t})$ & $(t)$ \\
\hline Total & I Launch Element Mass & 104.26 & 103.67 & 53.33 \\
\hline
\end{tabular}

\section{Summary and Conclusions}

A human exploration 1-year round trip mission to the NEA Apophis in the late 2020's is outlined that uses the basic NTR transfer vehicle in bimodal operation combined with a hybrid EP. The vehicle sizing analysis presented in this paper showed that by utilizing a hybrid NTR and EP system, up to $14.7 \mathrm{t}$ of launched mass can be saved over a similar conventional NTR vehicle. These weight savings allow significantly more margin for the inevitable dry weight growth that occurs during the prototype development design cycle. Additionally, the greater efficiency of the BNTEP can be used to enable a reusable ASV.

For either vehicle the heaviest launched element is the core propulsion stage. While it is possible to move more propellant into the drop tank element, this will start to affect both when the tank can be jettisoned, and the height limit of the launch vehicle fairing. If the drop tank contains more propellant for the first perigee burn it must then be held into the second perigee burn causing the overall vehicle mass to be higher than the optimal. Of course, the $\Delta \mathrm{V}$ split between these burns can be adjusted but that will cause higher gravity losses to be incurred. Also, as the drop tank length is increased and, in turn, the saddle truss length is also increased, additional structural mass for a longer saddle truss must be factored into the vehicle sizing calculations.

It may be possible to better distribute the mass between the 3 elements by locating the EP system within the short $12 \mathrm{~m}$ truss of the payload element. While not studied in detail, this design change would necessitate lengthening the truss to provide sufficient clearance for docking the MMSEV. Also, the EP booms would need to be longer to prevent plume impingement onto the aft end of the ASV. Another consideration with this design change would be the added mass of electrical wiring from the Brayton Power Units to the newly located EP thrusters. All of these modifications would result in a heavier launched mass. Relocating the EP system to the payload element may eliminate the need for canting the thrusters, provided the booms can be made with sufficient length. If so, the 
cosine losses would be eliminated, thus lowering the required xenon propellant mass. A trade study would have to be performed to determine if relocating the EP system is beneficial.

Another modification to the core stage would be to place the cylindrical section of the core stage Brayton radiator over the intertank adapter. This would eliminate some of the heat into the $\mathrm{LH}_{2}$ tank for the reusable version of the ASV and could save the mass of 30 layers of MLI as well as lower crycooling power. The downside is the intertank adapter would need to be larger to account for the required surface area. This could only be done if the core stage would still fit within the SLS payload fairing.

A round trip mission to Apophis is high energy and therefore harder to close using a conventional NTR approach. If reusability is desired, then vehicle closure is not possible with NTR, given the current SLS launch constraints. Waiving certain ground rules for the vehicle design is one way to attempt vehicle closure, but should not be tried early in the design cycle. Another method to aid in vehicle closure is to address changes in mission architecture such as reducing crew size and/or jettisoning the MMSEV and crew waste at the asteroid prior to returning to Earth. These methods were not addressed in the scope of this paper as a 1 year deep space mission is very taxing to human endurance for a crew of four let alone to a crew of three. In addition, jettisoning the MMSEV and waste material creates potential asteroid contamination issues for future explorers to address. Thus, BNTEP can be a key design option that would allow closure for a reusable vehicle.

While the proposed BNTEP vehicle shows a significant benefit in saving launched mass to orbit, it is not accomplished without additional complexity and therefore cost. The BNTEP vehicle requires at least 2 large scale mechanisms. The first is the retractable EP thruster boom. Not only does this boom have to be stowed for the launch configuration but it must also deploy and cant the EP thrusters. This means having flexible electrical and xenon fluid lines that extend with the boom. The second mechanism is the deployable radiator on the saddle truss. Large mechanisms trend to lowering the reliability of the vehicle. In addition to the large mechanism issue, BNTEP also requires scaling the Brayton power and EP system by at least an order of magnitude in size and output over the current state of the art. Locating all the required area for the BPC radiator was an issue because part of the core tank was exposed to its additional heat input, necessitating extra insulation. For the expendable version of the BNTEP vehicle, this was not a significant issue, since all the hydrogen propellant was used during TNI. Heat input to the core tank from the Brayton radiator was more problematic for the reusable hybrid vehicle, since the final Earth capture burn was performed with the remaining propellant in the core tank. Finally, The $\mathrm{UO}_{2}-\mathrm{W}$ cermet engines used for BNTR propulsion need a significantly larger quantity of highly enriched uranium than do the conventional NTR NERVA-derived engines. All of these points need to be considered to determine whether the cost/benefit ratio warrants developing a BNTEP vehicle.

\section{Acknowledgments}

The authors express their thanks to John Warren and Chris Moore (NASA/HQ), Mike Houts (MSFC), also John Taylor, George Schmidt and Mark Klem (GRC) for their interest in the BNTEP concept and funding support through the Advanced Exploration Systems' Nuclear Cryogenic Propulsion Stage (NCPS) project.

\section{References}

\footnotetext{
${ }^{1}$ Borowski, S. K., McCurdy, D. R., Packard T. W., "Nuclear Thermal Propulsion (NTP): A Proven Growth Technology for Human NEO/Mars Exploration Missions," IEEE Aerospace Conference, March 3-10, 2012.

${ }^{2}$ Dudzinski, L., Borowski, S. K., "Bimodal Nuclear Electric Propulsion: Enabling Advanced Performance with Near Term Technologies", $38^{\text {th }}$ Joint Propulsion Conference and Exposition, AIAA-2002-3653, July 7-10, 2002.

${ }^{3}$ Barrett, M. J., Johnson, P. K., "Performance and Mass Modeling Subtleties in Closed-Brayton-Cycle Space Power Systems," NASA/TM 2005-213985, Nov. 2005.

${ }^{4}$ Oh, D. Y., "Evaluation of Solar Electric Propulsion Technologies for Discovery Class Missions," AIAA-2005-4270, 2005.

${ }^{5}$ Florenz, R., Gallimore A. D., and Peterson P., "Developmental Status of 100-kW Class Laboratory Nested channel Hall Thruster," International Electric Propulsion Conference, IEPC-2011-246, Sept. 11-15, 2011.

${ }^{6}$ Frisbee, R. H., "Advanced Propulsion for the XXI ${ }^{\text {st }}$ Century," AIAA/ICAS Internation Air \& Space Symposium and Exposition, AIAA-2003-2589, July 14-17, 2003.

${ }^{7}$ Patterson, M., Ion Propulsion, NASA Facts FS-2004-11-021-GRC, Nov. 2004.

${ }^{8}$ Borowski, S. K., McCurdy, D. R., Packard T. W., "Modular Growth NTR Space Transportation System for Future NASA Human Lunar, NEA and Mars Exploration Missions," AIAA Space 2012 Conference \& Exposition, AIAA-2012-5144, Sept. 11 13, 2012.

${ }^{9}$ Burke L. M., Borowski S. K., McCurdy D. R., Packard T. W., "A Crewed Mars One-year, Short-stay Mars Mission using Bimodal Nuclear Thermal Electric Propulsion (BNTEP)," AIAA Joint Propulsion Conference, AIAA-2013-4076, July 14-17, 2013.
} 
${ }^{10}$ Giorgini, J. D., Benner, L.A.M., Ostro, S. J., Nolan, M. C., Busch M. W., "Predicting the Earth encounters of (99942) Apophis," Icarus 193 (2008), Sept. 5, 2007.

${ }^{11}$ Noland, D., "5 Plans to Head off the Apophis Killer Asteroid," Popular Mechanics, Nov.7, 2006.

${ }^{12}$ Beatty, J. K., “Asteroid Apophis Takes a Pass in 2036,” Sky and Telescope, Jan. 9, 2013.

${ }^{13}$ Wagner S., Zimmerman D., and Wie B., "Preliminary Design of a Crewed Mission to Asteroid Apophis 2029-2036," AIAA/AAS Astrodynamics Specialist Conference, AIAA-2010-8374, August 2-5, 2010.

${ }^{14}$ Borowski, S. K., McCurdy, D. R., Packard T. W., "Near Earth Asteroid Human Mission Possibilities Using Nuclear Thermal Rocket (NTR) Propulsion," AIAA Joint Propulsion Conference \& Exhibit, AIAA-2012-4209, July 30 - Aug. 1, 2012.

${ }^{15}$ Ocampo, C., Senent, J., "The Design and Development of COPERNICUS: A Comprehensive Trajectory Design and Optimization System," Proceedings of the International Astronautical Congress, IAC-06-C1.4.04, 2006.

${ }^{16}$ Joyner, C.R., Phillips III, J.E., Fowler, R.B., Borowski, S.K., "TRITON: A TRImodal capable, Thrust Optimized, Nuclear Propulsion and Power System for Advanced Space Missions," $40^{\text {th }}$ AIAA Joint Propulsion Conference, AIAA-2004-3863, July 11-14. 2004. 